\title{
CORRECTION
}

\section{Correction to: Experimental and Computational Characterization of Oxidized and Reduced Protegrin Pores in Lipid Bilayers}

\author{
Mykola V. Rodnin ${ }^{1} \cdot$ Victor Vasquez-Montes $^{1} \cdot$ Binod Nepal $^{2} \cdot$ Alexey S. Ladokhin $^{1} \cdot$ Themis Lazaridis $^{2,3}$ (D)
}

Published online: 30 June 2020

(c) Springer Science+Business Media, LLC, part of Springer Nature 2020

\section{Correction to:}

The Journal of Membrane Biology (2020) 253:287-298

https://doi.org/10.1007/s00232-020-00124-3

The original version of the article was published without the Graphic Abstract. Graphic Abstract image of the article is given below

Publisher's Note Springer Nature remains neutral with regard to jurisdictional claims in published maps and institutional affiliations.
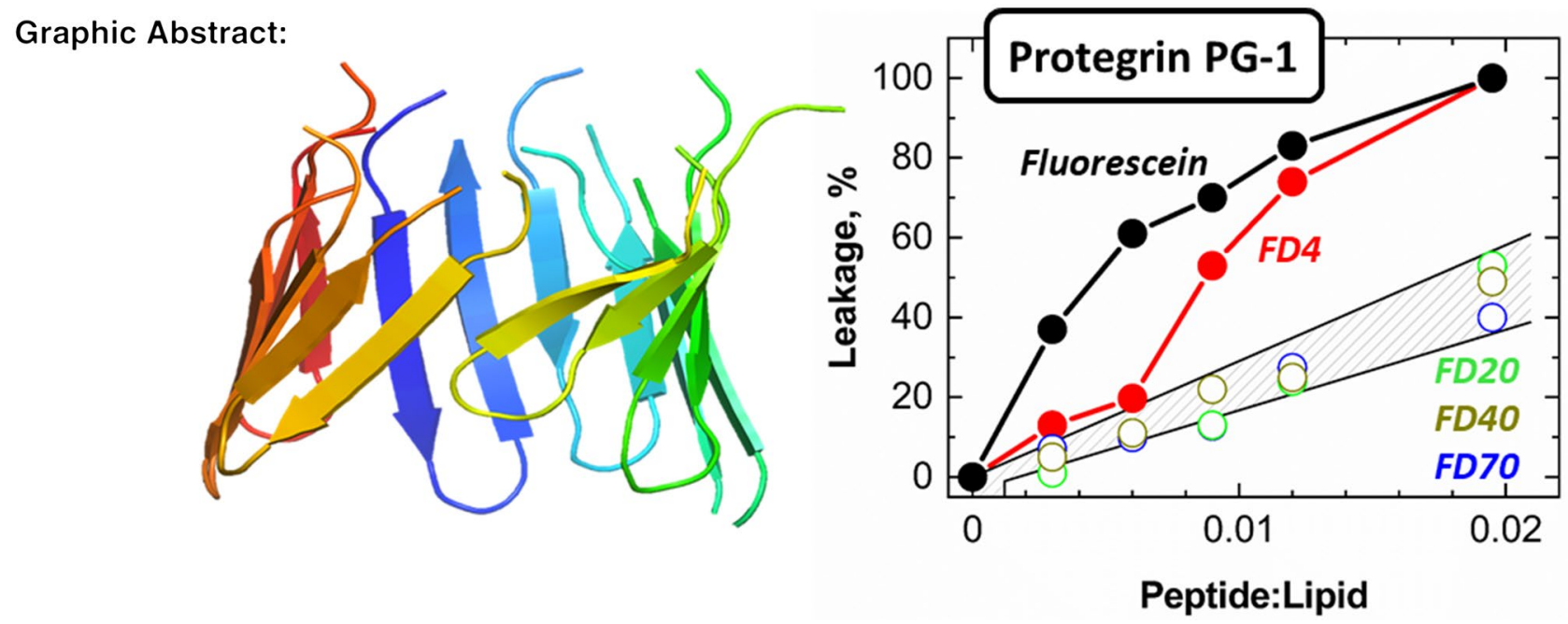

The original article can be found online at https://doi.org/10.1007/ s00232-020-00124-3.

Alexey S. Ladokhin

aladokhin@kumc.edu

$\triangle$ Themis Lazaridis

tlazaridis@ccny.cuny.edu

1 Department of Biochemistry and Molecular Biology,

The University of Kansas Medical Center, Kansas City,

KS 66160, USA

2 Department of Chemistry and Biochemistry, City College of New York, New York, NY 10031, USA

3 Graduate Programs in Chemistry, Biochemistry, and Physics,

The Graduate Center, City University of New York,

New York, NY 10016, USA 